\title{
Temperament, Character and Behavior in the Structure of Personality
}

\author{
Akhmet Dyussenbayev \\ Institute of physiology of man and animals of the Ministry of education and science, \\ Republic of Kazakhstan
}

\begin{abstract}
Existing classifications of temperament, characters, personality types and ways of behaviour are the disputable issues of the present-day scientific world. The origins of the classifications rise from the ancient philosophy and medicine in China and India (VIII BCE), Greece (V BCE), Rome (II century AD), England and Germany (XIX century), USA and Russia (XX century). Tremendous amount of the classifications were worked out all over the world and not all of them withstood the test of time. The references to Hippocrates' and Claudius Galenus' classifications occur chiefly, which are tangential with regard to mentality and psychic setup and based on humoralism (humorism). Great empirical and experimental materials have been accumulated in scientific history without harmonious systematization in view of the absence of the integrated international system of classification that is the factor restraining the further development of typology. There were curious incidents during typology march. Fourier described three hundred characters, for instance. Unfortunately, any ordinary person could not be able to remember all these descriptions. Since then, researches, finding and admission of the optimum types became the task of paramount importance for the scientists.
\end{abstract}

Key words: temperament(TR), character (temper) (CR), personality type (PT), behavioral style (BS)

\section{TEMPERAMENT}

Temperament or one's psychophysiological type (Genotype) is the genetic instinctive hereditary base of individual and typological differences of CNS (Central Nervous System) psychodynamic characteristics localized in chromosomes.

The neurophysiologic potential imparts the following seven key characteristics to the psychophysiological constitution of human beings: emotionality, dynamics, lability, flexibility, static nature, inertness and sensitiveness. The appropriate type of psycho-physiological constitution stands out against the others as a result of the dominance of one of these properties. 


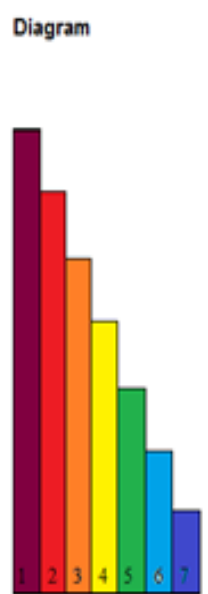

Nit

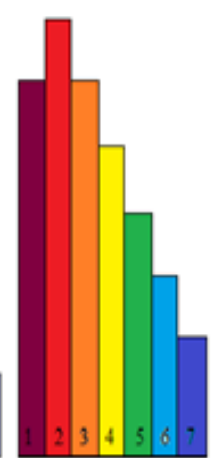

$\mathrm{N} 2$

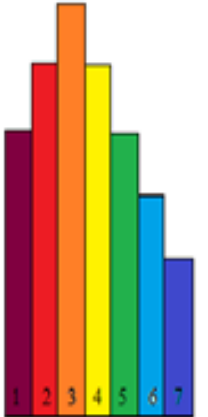

Nis

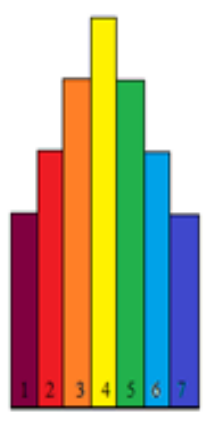

Nat

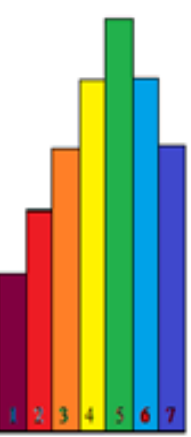

NG

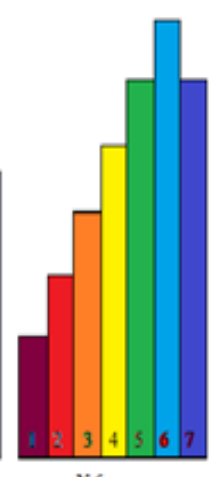

Na6

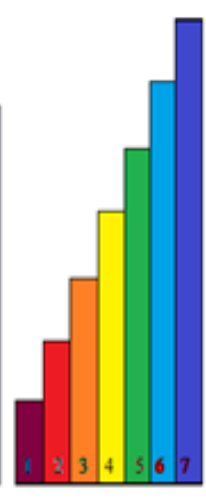

M?

Emotional type Dynamic type Labile type Plastic type Static type Inert type Sensitive type 1 - emotionality. 2 - dynamics. 3 - lability. 4 - flexibility. 5 - static nature. 6 - inertness. 7 - sensitiveness.

\section{Emotional type (anxious, uneasy)}

Representatives of this genotype are genetically predisposed to quick and impressive display of psychic anxiety, excitement, rages and even affect, being overjoyed or crying (weeping) with joy. Their psychical activity is rich with striking emotions. They are easily excited, agitated, and with it, excessively irritable persons possessing the highest level of energy mobilization of their organisms. It is possible to call them figuratively as 'Hawks'.

\section{Dynamic type (energetic, assertive)}

Persons of this group are possessed of permanent movement, internal force and active actions during all their life. They are always sthenic, spirited, strenuous and vigorous. The balance and easiness of excitation and inhibition beginning imparts steadiness to the nervous system. The velocity and successfulness of their accommodation and adaption are precisely this fact that explains. The figurative image of such person is 'An eagle'.

\section{Labile type (unsteady, changeable)}

The genotype endows the persons with changeability, changeableness, mutability, unsteadiness, fickleness, variability and extraordinary functional mobility. Immediacy of their main neurophysiological processes becomes the prerequisite for the maximal adaptability that is the faculty of accommodation to the quickly changed environmental conditions. Thus, we may call them 'Magpies'.

\section{Plastic type (flexible, malleable)}

All of the persons, who may be attributed to this genotype, are harmonious, gradual, slow, gentle and pliable. Their maximally balanced neurophysiological processes and poised nervous system with its proper force, staying power and fortitude impart excellent adaptability to all the individuals of this genotype giving them the natural ability of ultra instinct of selfpreservation and survival by means of escape behavior. Their image is 'An ostrich' and it is no coincidence.

\section{Static type (steady, equable)}

Their "active" movement and actions are barely visible in their outward appearance and the neurophysiological processes run in the state of comparative quiet and mental equilibrium. 
Their characteristic is 'A swan'. They are so imperturbable that the following wishes are quite appropriate.

\section{Inert type (solid)}

Inert persons are inactive and spiritless to the eye. The level of their general motion activity is too low; the neurophysiological processes are over moderated but rational. Meanwhile, their nervous system is quite balanced and capable of great endurance. We usually say about them, 'By hook or by crook' and their characteristic for us is 'A goose'.

\section{Sensitive type (careful)}

The genotype makes the persons very sensitive, especially to the irritants of subliminal force. Thus, the individuals are able to reacts to any environmental exposure keenly, even it is weak and insignificant. The factors create susceptibility to the affective reactions so the individuals are rather impressionable and may be compared with 'Owls'.

\section{CHARACTER}

Character (Phenotype) is totality of settled individual characteristics of psychical activity formed during the process of adaptive ontogenesis development and based on the psychophysiological constitution matured as the result of individual upbringing.

Physiological processes give human beings the following seven distinct qualities: hysteroidness, impulsiveness, flexibility and agility, conformity, correctness, criticality and sentimentality. The appropriate type of character appears as a result of the dominance of one of these qualities over the others.

$$
\text { Diagram }
$$

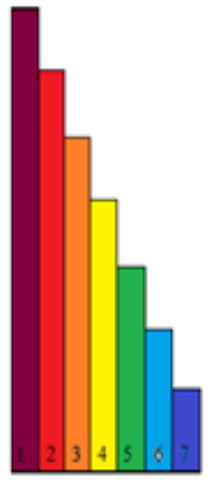

$\mathrm{Ni}$

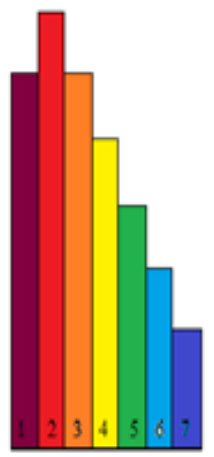

N2

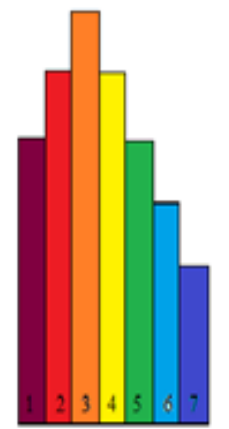

N3

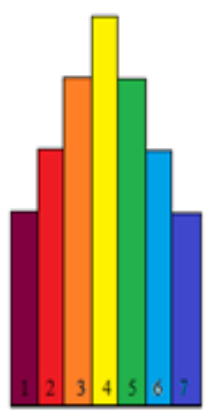

Nat

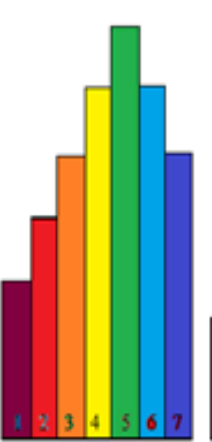

NS

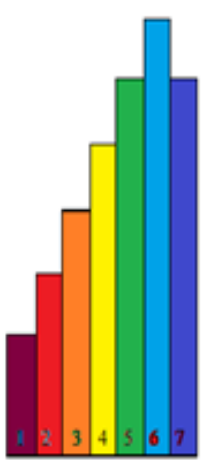

No6

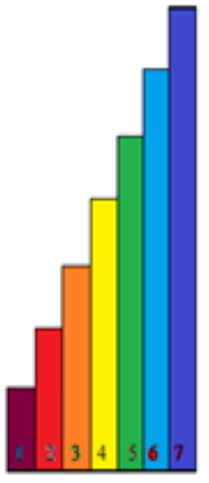

N7

Hysteroidal Impulsive Flexible Conformal Well-posed Critical Sentimental 1 - hysteroidness. 2 - impulsiveness. 3 - flexibility and agility. 4 - conformity. 5 - correctness. 6 - criticality. 7 - sentimentality.

\section{Hysteroidal (explosive)}

People possessing such kinds of temper are predisposed to violent fantods and sometimes attacks of nerves, which manifests itself in unexpected changes of their mood from convulsive laughter to tears and vice versa. They are usually at a very excited state, warlike and characterized by increased irritability and restlessness. Their mental activity may be often upset being gotten to inadequately situations and so the persons are able to raise their voices getting positive or negative tone. This is the most unbalanced character - 'rudderless and without sails'. They are like a source of bizarre surprises. 


\section{Impulsive (energetic, pushing)}

Such people are usually highly purposeful and possess strong inner urges. They are energetic, active and assertive with strong-willed motives. Strong feelings and elation are accompanied by the desire to realize their potential, even in the presence of obstacles. These properties open for them the way to the more creative impulses and not just creative! They tend to noble deeds. Their nature is more adventurous. They tend to live according to the principle 'as well be hanged for a sheep as for a lamb', that is, with a thirst for subjugation the heights.

\section{Flexible (agile, nimble, adroit)}

These people know how to avoid obstacles without much effort and capable of quick and easy movements, alteration, modification and reconsideration. They are pragmatic, easy to change their attitudes, beliefs and habits turning to advantage and receiving all of the benefits and dividends. They are masters of intrigue. They are changeable but courteous and if necessary are able to put the other in an awkward situation. They usually act prudently and cleverly avoid potential hassles. Thanks to the resourcefulness skillfully uses the capabilities of other people, skillfully manage their own reserves but often resort to tricks and maneuvering. Camouflage fits them aptly. In short, 'Necessity is the mother of invention'.

\section{Conformal (compliant, pliable)}

Such people are always ready to act in accordance with the established order. They try to meet the requirements of others. Their docile nature allows them to adapt themselves without conflicts and obey. In most cases, the individuals prefer the passive acceptance of the existing order of things and prevailing opinions. They are the most livable people. They are beautiful because of the harmony of their actions and smooth attitude towards others. They are malleable and prefer to make concessions and effectively resolve conflicts between their own and dominant opinions of the other individuals. In general, their purpose is 'the wolves are fed and the sheep are safe'.

\section{Well-posed (proper, consistent)}

This individual is able to defend his principles peacefully and remain quite friendly and sensitive to other people at the same time. Sometimes he may be pointedly polite. He does everything perfectly and corresponds to the reasonable requirements of the life. His behavioral approach fits many social standards. This type is like an etalon for the extreme types in pedagogy because such a person is comfortable to all and gives his teachers the least troubles. Such persons are adequate without being forced and it is usually said about them - 'The man is intelligent but pedantic'.

\section{Critical (exacting, scrupulous)}

Such people are unique with their inclination to analyze their own actions and deeds in details and evaluate strictly as well as the actions of others in order to identify shortcomings and failures. They often allow negative judgments about themselves and others and this creates a lot of problems for them. They are not as enterprising as picky. However, their captiousness and fault-finding are based on "the best intentions". However, the people around them estimate their actions as inertness and stubbornness. This individual has an analytical mind and a critical attitude to everything. This is the main feature of this type of character. Their motto - 'Measure twice but cut once' and the appropriate synonym is 'Nordic'. The following statement is very suitable for the characteristics of the individual. 


\section{Sentimental (refined, subtle)}

A man of this type of character is prone to excessive sensitivity. He possesses sugary-sweet and tearfully-touching type of character. He is very impressionable, gentle, corny, bashful and touchy. He is like a mimosa and likes to dramatize events very much. He usually treat others too softly and indulgently. He is the most kind and humane among the other types. He can be compared with the 'The Man in a Case' (story by A. Chekhov) if his living conditions are unfavorable. He is prone to hyper analysis or sterile philosophizing. L. Berne said about this type of character: 'Sentimental individuals churn their sense long and tediously'. They are like potential inhabitants of the 'Barrel of Diogenes.' But we should not forget that the 'Still waters run deep'.

\section{BEHAVIORAL STYLE}

Behavioral style (Ethotype) is a conscious choice of morals and strategy actions reflecting the type of innate psycho-physiological constitution, formed character and values of the individual orientation. Avicenna's thoughts are harmonious with the following definition: 'The essence is reflected in your being. It cannot be a secret for a long time. The essence of any nature is visible in persons' actions as if in a mirror, is not it?

The features of mental activity give human behavior the following seven relief signs: expressiveness, ostentation, dexterity quotient, capability to agree to a compromise, tactfulness, categoricity and depressiveness. As a result, the dominance of one of these signs over the others forms the appropriate behavioral style.

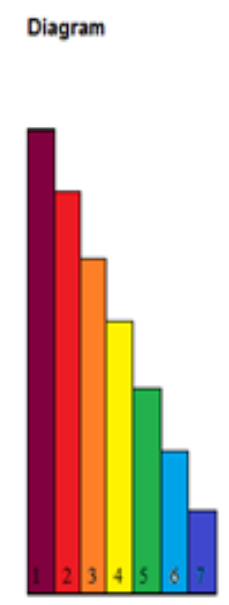

N1

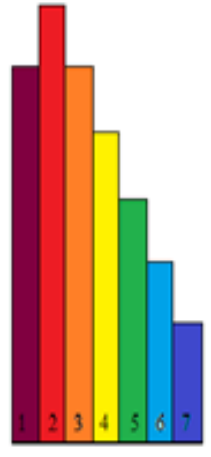

Nis

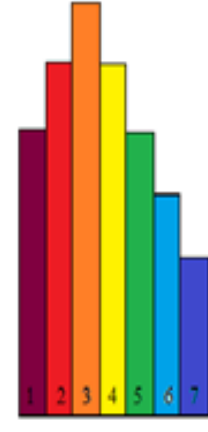

N3

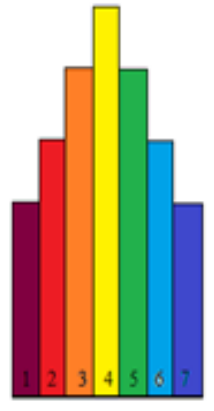

N4

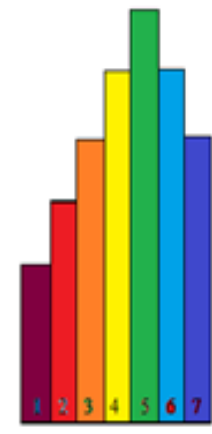

M

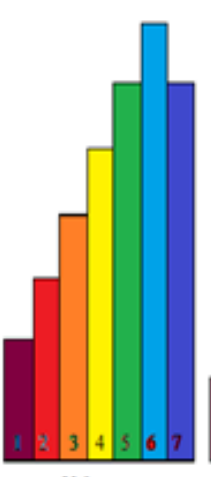

No6

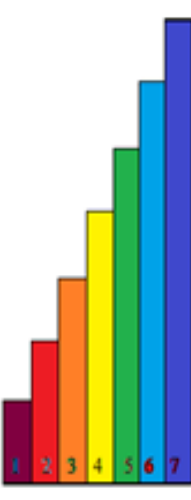

N7

Expressive Demonstrative Manipulating Compromise Tactful Categorical Depressed 1 - expressiveness. 2 - ostentation. 3 - dexterity quotient. 4 - capability to agree to a compromise.

5 - tactfulness. 6 - categoricity. 7 - depressiveness.

\section{Expressive (unrestrained, impetuous)}

The people of the group are prone to overly rapid and often ill-considered actions. Fussy and superficial attitude to everything is inherent in them. Their joy and despair are usually expressed excessively and brightly. Their experiences do not often possess the proper occasion and are underlined with nervous irritability. They are inclined to reflect their emotional state dramatically. They are expressive both in life and in creative work. They may be referred to Music among the seven secular sciences of the Middle Ages. It is difficult to say if they are positive or negative persons because it is a particular question of culture, religion, morality, 
ethics, spirituality and moral code (W. A. Mozart, A. S. Pushkin, L. Trotsky, H. Truman, N. Khrushchev, Jr. G. Bush).

\section{Demonstrative (manifest, indicative)}

The most important thing for these people is to show their best sides. They are characterized with external showiness bordering on grotesquerie. They are hedonics and crave intensity of stress and frenzy. They are able to mobilize all their forces to achieve certain results and then publicly advertise their achievements. They are deft rhetorics. Their quick wits and insatiable desire to be in a fishbowl gives them a resounding success or failure (Odysseus, Attila, Genghis Khan, Ch. Columbus, Tamerlane, H. Nelson, B. Napoleon, O. Bismarck, I. Grozny, G. Washington, A. Suvorov, Ch.de Gaulle, Che Guevara E., J. Kennedy, Y. Gagarin, M. Monroe, M. Thatcher).

\section{Manipulating (resourceful, dodgy)}

So-called "Manipulators" can cleverly pass audience off things to be hidden. They are very gifted to counterfeit anything skillfully. They pass round sharp corners strikingly and are able to manipulate others, influence them, work up their electors as well as juggle with facts and falsify them. They may be called 'Arithmetics'. Their cunning tricks are aimed for achieving the results of easy and substantial benefits for themselves. They don't give a damn (A. Mesmer, G. Rasputin, R. Reagan, M. Gorbachev, A. Kashpirovskiy, A. Akopian, N.Sarkozy, S. Mavrodi, D. Copperfield (Kotkin).

\section{Compromise (yielding, pliant)}

People of this behavior type reach to agreement easily by mutual concessions. They are conciliators and compromisers. Stendhal expressed his opinion about them as follows, 'Mind flexibility can replace the beauty'. They often change their survival tactics as well as their not abundant principles. The characteristic of this individual is a "Great scribe'. Their external manners are refined but their self-esteem is not always expressed. However, most people appreciate this style of behavior, because such persons give others least of problems and profit. Thus, the stagnation is the drawn effect only (M. Kalinin, L. Brezhnev, K. Chernenko).

\section{Tactful (civil, courteous, considerate)}

Tactful people have a sense of proportion that prompts them the most delicate line of conduct in relation to other people. They are endowed with their own principles but they do not tend to put them on display. Smoothness and uniformity of behavior are inherent for them as well as the sense of proportion in all determining and developing the ability to behave themselves. They can be called Geometricians. This behavior is like an undercover etalon in the questions of upbringing and good breeding for families in many nations. Two natural antagonists assurance and lack of tending to argue or quarrel - are a phenomenon of the most harmonious co-existence, as a kind of 'consensus' and inner harmony. It should be remembered that the absence of a devastating inception does not mean constructive endeavour, whereas (Ch. Darwin, R. Descartes, M. Kutuzov, A. Lincoln, G. Titov, Ch. Aitmatov, D. F. Spencer).

\section{Categorical (unambiguous, unequivocal, monosemantic)}

Their approach to themselves and other people is clear, unambiguous, unconditional and unequivocal, not allowing any objections, as a rule. Their logical proposition is quite definite and excludes any duality; their outlook is not veiled, crisp; it is clear and not allowing any other interpretations. Their actions are always straightforward and resolute. Goethe was right when he said, 'When ideas meet temper, the phenomena appear amazing the world for thousands of years'. We can call them Dialecticians. They are true to their ideals and do not compromise their own principles. Such a person is a 'white crow' in one place in the world and one of many 
in the others. Their bright personality can enrapture and horrify (F.-M.A.Voltaire, J.S.Bach, W.R.Wagner, L. Pasteur, I.Kant, F.Dostoevsky, R.Ch.K.Diésel, G.R.Ford, W.Churchill, F.D.Roosevelt, B. Yeltsin).

\section{Depressed (dispirited, oppressed)}

People of this type are sad, cheerless, doleful, dismal, despondent, crestfallen, downcast and oppressed in the most part of their life. They continually give the blues to others with their depressed mood. Their predisposition to this condition is genetic. They are prone to apathy and pessimism. They possess infinitely bad mood due to the decline of fortitude. People of this type are slowpoke, sleepy, fatigued and have reduced self-esteem. Their characteristic is Astronomers. Their ability to desire, being motivated, strong-willed activity is dramatically reduced, which provides spaciousness of thoughts, imagination, abstraction and violent fantasies (F. Chopin, F. W. Nietzsche, T. T.Heine, N. Gogol).

\section{PERSONALITY TYPE}

Personality type (Egotype) is a fusion of congenital and acquired and socially determined qualities of an individual knowingly predetermining his or her personal motivational orientation and ideological preferences with respect to the surrounding reality.

Being aggregated temperament, character and behavior give the following seven distinctive characteristics to individuals: eccentricity, demonic, combinatorial, convergence, tolerance, unruffled and self-centeredness. The contours of the appropriate type of personality are clearly delineated as a result of the dominance of one of these signs over others.

$$
\text { Diagram }
$$

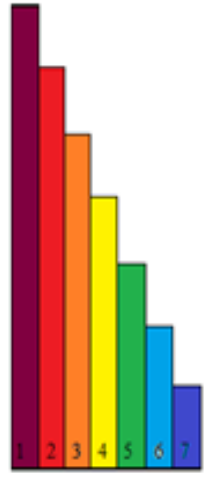

M.1

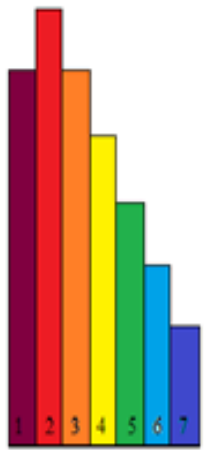

M.2

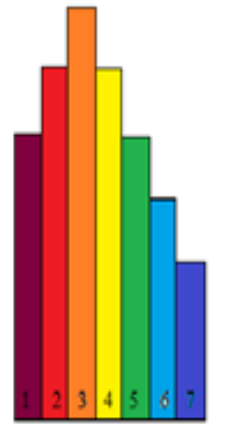

Ms

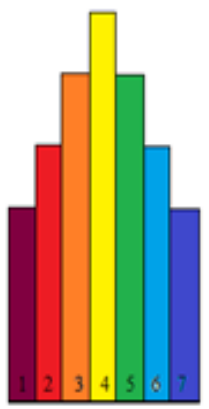

Nat

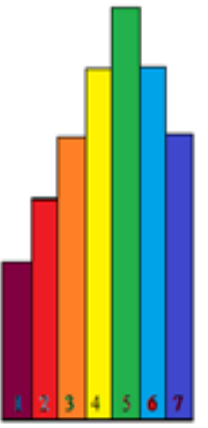

Ms

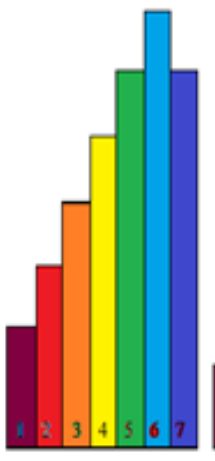

N.6

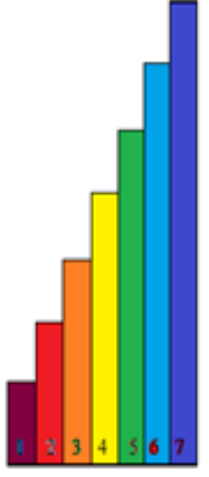

M?

Eccentric Demonic Combinative Convergent Tolerant Nordic Egocentric 1 - eccentricity. 2 - demonic. 3 - combinatorial. 4 - convergence. 5 - tolerance. 6 - unruffled. 7 - self-centeredness.

\section{Eccentric (unpredictable, unexpected)}

People of this type are prone to sudden sharp contrast freaks in the form of excessive joy or aggressiveness. They are distinguished with their extreme originality or their tactless behavior and immediacy. Their actions strike with their unexpectedness, exaltation or enthusiasm. They are somewhat strange, original and sometimes quizzical. Everything in them is based on a bizarre shift of familiar concepts. Their behavior is inconsistent and out of the ordinary. As M.Servantes wrote, 'Courage without prudence is folly'. Each representative of this group is an unstable extrovert. Their status quo is a Hot Rodder. 


\section{Demonic (imperious, dictatorial)}

Each representative of this group is bold, decisive and a man possessed with something and sometimes raging. Their compassion, generosity and sociability get on with guile. It is difficult to be a domineering man without craft, cunning, duplicity, craftiness and perfidy, as they think. They are tribunes, cheery fellows and "Life of the party". They tend to suppress somebody's will in order to stay longer in the spotlight. They are mainly the people of a stage monologue genre. They are eloquent, sociable and fervent. Their passion and fervor may often reach mischief. They are maximalists and virtuosi and may be extraordinarily gifted. They are naturally talented as organizers and leaders. Moreover, they always strive to become leaders. Their motto is created under Goethe's thoughts to 'know your own nature through actions just not through contemplation'. They are stable extroverts facing the outside world. They may be called Hegemons. Their status quo is Leaders. The Persian poet Khosrow pointed to the paradoxical trait saying about them as follows, 'A narcissistic lion with claws and fangs, which may be touchy like a flower with trembling petals'. Thus, authoritarianism, totalitarianism, cult of the leader, patriarchal character, repressions and other excesses become the results of their personality type.

\section{Combinative (cunning, intricate)}

They are able to design and build a complex system of techniques to achieve the desired useful and adaptive result. They are able to achieve their goals by different machinations maneuvering among the natural and artificial barriers. These individuals are intricate and incomprehensible to others. They have a special gift to various tricks and bluffs. Their personality type is deep-seated. They are extra ambiverts and their status quo is 'Gamblers'.

\section{Convergent (easy to get on with somebody)}

People of this type are conflict-free and usually prefer unobtrusive assimilation with other individuals. They excellently get on with others in any heterogeneous environment and create a favorable climate around neutralizing the problems of interpersonal origin. They are set on the convergence and the acquisition of similar features emulates their behavior under constraints of common sense. The purpose of their life is to live in peace with all on terms of mutual benefit. The founder of the Persian poetry A. Rudaki said the following about them: 'God gives the noble people such good qualities as a great name, reason, mild temperament and health of the body.' They are ambiverts. They can be called 'the golden mean' and their status quo is 'Peacemakers'.

\section{Tolerant (patient, long-suffering)}

Individuals of this type are unusually tolerant, indulgent and lenient to the near and distant relatives, friends and even strangers. As a rule, they are trusting to others. They endure psychological discomfort well. Their typological feature is self-control, self-possession, ability to tolerate long-term adverse effects without much reduction of adaptive capacity. They are intro ambiverts and their status quo is 'Soldiers'.

\section{Nordic (imperturbable, unruffled)}

People of this type adhere to the views placing their and others' individuality in the center of the universe. They respectfully refer to all manifestations of healthy individualism. They are sometimes selfish and have somewhat high self-esteem. By focusing on their own interests they stubbornly defend their views. They are thoughtful and pedantic and often alone. They were very popular in the era of technocratic society. They are stable introvert directed to their own inner world. Their status quo is 'Designers'. 


\section{Egocentric (separate, solitary)}

This type of people subtly perceives life changes. They are shy, timid, sensitive and prone to long emotional experience of events. They have a tendency to high moral demands to themselves. They are afraid of new situations, people and all kinds of tests. They are unstable introverts and their status quo is 'Philosophers'. The following statement may fit to their personality type, 'Chastity will definitely lose the struggle for existence without talking about struggle for the throne'.

Great empirical and experimental materials have been accumulated in scientific history without harmonious systematization in view of the absence of the integrated international system of classification that is the factor restraining the further development of typology. There were curious incidents during typology march. Fourier (Francois Mari Charles) described three hundred characters, for instance. Unfortunately, any ordinary person could not be able to remember all these descriptions. Since then, researches, finding and admission of the optimum types became the task of paramount importance for the scientists. As a result, the seven consecutive types presented below may fit the bill of this inveterate problem.

Human beings' minds are still weak before the eternal secret of the Universe and our own brain in spite of the fact that we live in the third millennium. Billions of neurons are like the galaxy stars not revealing their secrets. We use the formed behavior patterns in our daily life. Avicenna said his piece about human beings' nature many centuries ago. He thought that 'A human being's essence is reflected inside him and it cannot remain a secret for a long time as far as any person's actions reflect his nature like in a mirror'.

Banal actions, verbal forms and standard thoughts guard our brain against the superfluous routine. As a rule, people do not think long and human habits help them to do this. A.S.Pushkin expressed his opinion as follows 'Our habits are a gift given us from above and they may be a substitute for happiness'.

Our habits are an integral part of our behavior style. Our behavior style is our essence reposing on "The Three Whales", which are Psychological and physiological constitution (Temperament), Temper and Personality type. Temperament is a hereditary character. One's temper is formed by the age of 17 and personality formation is competed by the age of 25 . Temper evolution and personality progress are started with the moment when any human being is given a birth. Temperament prevails before children reach the age of seven. After that our native quality called psychological and physiological constitution starts to be covered with acquired qualities intensively. They are temper parameters. Individual temper is formed on the base of neurobiological temperament. Next, the social product called personality type is covered with various propensities.

In the beginning the author modeled a 'Universal seven-digit classification' consonant with the laws of symmetry and harmony and religion dogma thanks to the number theory and mathematics canons. The figure "Seven" is mentioned 144 times in the Holy Bible and it is not randomly. This figure is consonant to poetry as well.

The poet A.Voznesenski paid attention to the fact. He wrote the following poem about this figure, 'I am a family. I am like a spectrum, where I am multiplied by seven and all my seven copies are living inside me. All of the copies are intolerable like seven animals. Moreover, the 
bluest one is whistling a reed pipe! Sometimes in spring I have a dream, where I am the eighth one among them'.

Being based on the achievements of the up-to-date science we are glad to present your attention the principally new classification consisting of three main levels of human being's essence. Temperament is a psychological and physiological aspect. Temper is psychological one and behavior style possesses a social reflection. Behavior style is habitual daily routine that is reasonable vival functions based on the stereotypes.

We would like to note that the presented classification was reviewed by the scientists from the West and Russia. This meaty scientific study assists to carry out an interesting psychological practical training session as well as to develop your observation. What is the personality type of the person living or working beside you? What is your own temper?

The typology proposed by the author possesses a little bit of novelty letting to see the habitual things from the new perspective. The quite modern structure of personality is presented instead of the catchwords like "choleric, sanguine, phlegmatic and melancholic persons" allowing opening human beings' tempers deeper and wider even when you know the people for a long time.

Having examined the new classification of the personality structure you may start determination of the types of psychological and physiological constitution and temper. Then you may identify what the personality type may be referred to you and all the people you want to.

Using the newly presented classification you may possess the complete notion about the persons around you and compose their characteristics having analyzed their behavior.

\section{INTRODUCTION}

However, I. Pavlov's classification of the nervous system types is the most determined but fourdigit though. I.P.Pavlov classifies types of higher nervous activity according to several attributes that considered as most reliable indices of higher nervous activity. These were intensity of the excitation and inhibition, the ratio of these processes in central nervous system and their mobility, that is rate at which excitation was replaced by inhibition and wise versa. In experimental practice the following four principle types of higher nervous activity are met:

1. Strong unbalanced type, characterized by predominance of excitation over inhibition;

2. Strong well-balanced active type, characterized by high mobility of nerve processes;

3. Strong well-balanced passive type, characterized by low mobility of nerve processes;

4. Weak type, characterized by extremely weak development of both excitation and inhibition, which cause fatigue and low workability. Type of nervous system after I.P.Pavlov.

\section{References}

1. Aizenk G.Y. (1999). Personality structure. St.-Petersburg: Uventa, Publishing House KSP-Plus. Moscow. p. 464.

2. Bekhterev V.M. (1991). Objective psychology. Moscow: Science. - p. 480.

3. Godfrua J. (1992). What is psychology? 2 volumes. Translation from French. - Moscow: World. - p. 872.

4. Dyussenbayev A.R. (1988). Methods of determining the individual typological characteristics of higher nervous activity in birds. Questions of the physiology of higher nervous activity. Proceedings of the 
Institute of Physiology Academy of Sciences of the Kazakh SSR. Volume 33. - Alma-Ata: Publisher "Science." pp. 58-72.

5. Dyussenbayev A.R. (1989). The new classification of the types of nervous system. All-USSR Conference of the Society of Psychologists of UUSR. - Moscow. - pp. 23-24.

6. Dyussenbayev A.R. (1990). Brief characteristics of the types of higher nervous activity. Materials of Conference of the Institute of higher nervous activity and neurophysiology at Academy of Science of USSR «From conditioning to thoughts». - Moscow. - pp. 31-32.

7. Dyussenbayev A.R. (1990). Conditioning of the hens of various types of higher nervous activity. News by Academy of Sciences of KazSSR, Biological series. - Alma-Ata, No.2, - pp. 81-87.

8. Dyussenbayev A.R. (1990). The types of higher nervous activity and steadiness to stresses of hens. Informational publication of agricultural science of Kazakhstan. - Alma-Ata, No.1, - pp. 66-69.

9. Dyussenbayev A.R. (1991). Classification of types of psychic activity. Abstracts. London conference. The British Psychological Society. - London: City University. - pp. 28-29.

10. Dyussenbayev A.R. (1991). Specific and typological peculiarities of inter-signal reactions of hens. News by Academy of Sciences of KazSSR, Biological series. - Alma-Ata, No.6, - pp. 83-85.

11. Dyussenbayev A.R. (1991). Classification of the types of higher nervous activity taking into account the peculiarities of thinking. Materials of Conference «Individual psychological and physiological peculiarities of human beings and professional activity». - Kiev. - pp. 93-94.

12. Dyussenbayev A.R. (1991). Experimental and theoretical premises on development of the new type classification of higher nervous activity. News by Academy of Sciences of KazSSR, Biological series. Alma-Ata, No.6, - pp. 16-26.

13. Dyussenbayev A.R. (1991). Classification of the types of higher nervous activity taking into account the peculiarities of the analytical and synthetic brain activity. Materials of the First Congress of physiologists in Central Asia and Kazakhstan. - Dushanbe. - pp. 128.

14. Dyussenbayev A.R. (1991). Main lines of conditional and reflectory memory. Materials of the First Congress of physiologists in Central Asia and Kazakhstan. Dushanbe. - pp. 127.

15. Dyussenbayev A.R. (1991). Temperament as the neuron and dynamics foundation for psychological dynamics and the types of higher nervous activity. Materials of the First Congress of physiologists in Central Asia and Kazakhstan. - Dushanbe. - pp. 129.

16. Dyusenbayev A.R. (1998). Artikel "Die Struktur der Persönlichkeit". Die Zeitung "Euroasiatischer Kurier." - Hamburg. Nr. 03 (07), 06.04. - 06.05. 1998. - Seite 12-13.

17. Dyussenbayev A.R. (1999). Classification of temperament, character, personality types and behaviors. International scientific conference "Problems of high school and applied science in the Republic of Kazakhstan." - Astana: Eurasian University. pp. 271-275.

18. Dyussenbayev A.R. (2004). Personality structure. New generation. - Almaty, April 09, 2004, No.14 (306), pp. 7-8.

19. Dyussenbayev A.R. (2011). Who is who? Journal «Thought». - Almaty, No.3, - pp. 27-33.

20. Dyussenbayev A.R. (2012). New classification of personality structure. Journal of the Institute of Philosophy and Political Science of Kazakhstan "Man's World." - Almaty, № 2. pp. 97-109.

21. Dyussenbayev A.R. (2013). Types of temperament, character and behavior of the person. Psychological help: contents, forms, experience. Materials Ural-Volga region of the tenth seminar. Institute of consulting and training "Status". Orenburg state University, 24-27 November 2013. - Orenburg, 2014. - pp. 7-22.

22. Karpenko L.A. (1990). Psychology. Dictionary. Edited by A.V.Petrovsky. - The 2nd edition. - Moscow. - p. 494.

23. Nebylitsin V.D. (1976). Psychophysiological research of individual differences. - Moscow. - p. 335.

24. Nemov R.S. (2005). Psychology. - The 5th edition. General foundations of psychology. - Moscow. - p. 687.

25. Pavlov I.P. (1954). Physiological doctrine of nervous system types and temperaments. The types of higher nervous activity and experimental neurosis. - Moscow. - pp. 63-87. 
26. Pavlov I.P. (1954). General types of higher nervous activity of human beings and animals. The types of higher nervous activity and experimental neurosis. - Moscow. - pp. 144-145.

27. Russalov V.M. (1979). Biological foundations for individual and psychological differences. - Moscow. p.352.

28. Semagin V.N. (1971). Application of quantity characteristic of higher nervous activity types. Method of evaluation of higher nervous activity characteristics. - Leningrad. - pp. 131-140.

29. Semagin V.N., (1988). Zukhar A.V., Kulikov M.A. Nervous activity types, steadiness to stresses and reproductive function. - Moscow. - pp. 22-28.

30. Simonov P.V. (1981). Role of limbic structures in individual characteristics of behavior. Acta, neurobiology experience. Vol. 41, No.6, - p. 573.

31. Teplov B.M. (1956). Some questions of studying the general types of higher nervous activity of human beings and animals. Typological peculiarities of higher nervous activity of human beings. - Moscow. Volume 1. - p.310.

32. Teplov B.M. (1961). The problems of individual differences. - Moscow. - p.290.

33. Tyukhtin V.S., Urmantsev Y.A. (1988). System. Symmetry. Harmony. - Moscow: Thought. - p.315.

34. Chaichenko G.M. (1987). Psychology foundations of higher nervous activity. - Kiev. - p.176.

35. Jung K.G. (1998). Psychological types. Translation from German. - Minsk. - p. 656. 